\title{
Optimizing the order processing of customized products using product configuration
}

\author{
Hvam, Lars; Bonev, Martin; Denkena, B.; Schürmeyer, J.; Dengler, B.
}

Published in:

Production Engineering

Link to article, DOI:

$10.1007 / \mathrm{s} 11740-011-0334-x$

Publication date:

2011

Link back to DTU Orbit

\section{Citation (APA):}

Hvam, L., Bonev, M., Denkena, B., Schürmeyer, J., \& Dengler, B. (2011). Optimizing the order processing of customized products using product configuration. Production Engineering, 5(6), 595-604.

https://doi.org/10.1007/s11740-011-0334-x

\section{General rights}

Copyright and moral rights for the publications made accessible in the public portal are retained by the authors and/or other copyright owners and it is a condition of accessing publications that users recognise and abide by the legal requirements associated with these rights.

- Users may download and print one copy of any publication from the public portal for the purpose of private study or research.

- You may not further distribute the material or use it for any profit-making activity or commercial gain

- You may freely distribute the URL identifying the publication in the public portal 


\title{
Optimizing the Order Processing of Customized Products Using Product Configuration
}

\author{
L. Hvam ${ }^{1}$, M. Bonev', B. Denkena ${ }^{2}$, J. Schürmeyer ${ }^{2}$, B. Dengler ${ }^{2 *}$ \\ ${ }^{1}$ Department of Management Engineering and Operations Management, Technical University of Denmark, \\ Produktionstorvet, Building 426, room 41, 2800 Kgs. Lyngby, Denmark \\ ${ }^{2}$ Institute of Production Engineering and Machine Tools, Leibniz Universität Hannover, An der Universität 2 , \\ D-30823 Garbsen, Germany \\ *corresponding author: dengler@ifw.uni-hannover.de
}

\begin{abstract}
For the betterpart of the $20^{\text {th }}$ century many large companies have been focussed on optimizing their mass production process as a way of maximizing their profits. Nowadays, in the existing environment of global competitiveness, enhancing the production process remains a significant issue as well.

Product configuration based on integrated modular product structure and product family architecture has been recognized as an effective means for implementing mass customization. In order to evaluate the effects of product configuration on order processing, a study has been conducted by the Department of Management Engineering and Operations Management of the Technical University of Denmark in cooperation with the Institute of Production Engineering and Machine Tools of the Leibniz Universität Hannover. Thereby, a product configuration system has been modelled for a manufacturer of mass customized products and its benefits for the order processing have been evaluated.
\end{abstract}

\section{Keywords}

Product management, Product configuration, Order processing

\section{INTRODUCTION}

Optimizing the mass production of their goods, thus maximizing their profits, has been a major focal point for many large enterprises for the better part of the $20^{\text {th }}$ century and it remains a significant issue nowadays as well. In the past, the main concern of companies' executives was capacity, i.e. the ability to keep up with the increasing consumer demands. After several decades of continuous economic growth, by the 1950s many mass markets were saturated. Companies followed the strategy of diversification dividing the market into smaller segments. Consequently, the boundaries between the different markets started to blur. This enabled companies to produce even more of the same product and to utilize the advantages of mass production to an even greater extent. However, as companies moved into new markets, other competitors entered their earlier markets thus increasing the competition. This led to an intense global competitive environment, where companies had to be able to compete on prices, quality, delivery times, etc. In order to ensure their ability to competitiveness, companies started to differentiate their products even further. Moreover, they recognised that products sold in different regulations needed to fulfil country specific designs. As a result, customers received more options which led to their being more demanding: It was no longer enough to get the product, now it needed to satisfy certain ideas of design, quality and price. The product variety extended and the competition on the market grew.

Product configuration with the integration of modular product structure and product family architecture has been recognized as an effective means for implementing mass customization. Therefore, in order to achieve functional similarities among products that share common technology and production process, enterprises should begin with organizing manufacturing at the level of the product family [1].
To evaluate the effects of product configuration on the order processing, a study has been conducted by the Department of Management Engineering and Operations Management of the Technical University of Denmark. Thereby, a product configuration system for a manufacturer of mass customized products has been modelled and the benefits for the order processing have been evaluated. Chapter 2 describes fundamental information regarding modular engineering and product configuration. After that the case study presents the procedure of developing exemplary configuration systems and evaluates the impact of product configuration on the order processing (chapter 3).

\section{MODULARIZATION AND CONFGURATION}

\subsection{Modular Engineering}

In engineering design approach a module is often defined as a standardized unit and a combinable, changeable part or component. A module is a limited part of a product family with well-defined functions and pre-defined interfaces to the other modules in the product family [2,3]. Furthermore modules can be combined into a customized product according to a set of rules and constraints that regulate the validity of combinations of modules.

Modularity in engineering design is not limited to structuring a product only, but also an important basis for implementing lean and robust businesses in e.g. sales, design, production and installation. Modular engineering may be seen as a means for a business rationalization which helps balancing the challenges companies are facing nowadays. In fact, modular architectures can be considered as a way of securing a coordinated development of the product assortment and the business processes. In this context, modular engineering corresponds to the business strategy of systemic customization.

However, there are various factors which have an effect on a modular approach, which companies have to be 
concerned with (e.g. market conditions, stability of surroundings, design capability, maturity of architectural knowledge, technology maturity, initial investment) [4, 5]. For example, ERICSSON and ERIXON show in a model how activities towards lower complexity affect the different levels of the product architecture exponentially. Product architecture can be basically classified into three levels: the product range level, the product level and the component level. Each level has a different effect on reducing complexity. The model explains why product modularity mainly effects the product range level and brings advantages like higher flexibility in changing products for example [2]. VICTOR et al. apply a more detailed approach to modular engineering and divide modular sys tems into single-and multiple-systems. Single Systems contain the decoupling of a system (product) into subsystems (modules), in order to reduce the complexity and organize activities and resources. Multiple-systems, on the other hand, focus more on providing customization and variety through combinations of modules [6]. MILLER, for example, uses single systems in order to structure business with modular architecture of artefacts, activities and knowledge [5]. ZHANG simultaneously configures platform products and manufacturing supply chains. His approach poses the important challenge to find the optimum amount of modules [7].

ULRICH and TUNG distinguish between five different kinds of modularity [8]:

- In component sharing modularity same components are used in different product variants.

- In component swapping modularity different types of modules can be combined with the same basic module creating different product variants.

- The cut-to-fit modularity can be compared to the production of tailor made clothing where standard patterns are used to cut and fit the clothes to individual customers [9].

- A typical example for bus modularity is the computer industry where different components, such as graphic cards, are fixed on a motherboard.

- The selectional modularity possesses the highest degree of variety and customization. Here, the components are connected trough standard interfaces [8].

Modular construction systems can provide advantages in various areas along the product life-cycle. Modular systems reduce costs (economies of scale) and processing time of an order. In addition, changing the function of modules, as well as an extension of the product range, is possible. Modular design allows for increasing reuse and remanufacturing, as well as lowering separation costs for recycling. A disadvantage of modular engineering is that the modules are made general for any customer tailored product and thus not always optimal for the specific customer tailored product. E.g. a module may be larger and/or heavier than an individual designed part would have been. This means that working with modular products requires balancing the requirements for the overall performance and costs of the total product family and the sub-optimization of each product parts.

\subsection{Product Configuration}

No matter whether the product is modular or not, it is configurable if it is possible to eliminate any kind of uncertainty in the configuration activities. The product can be defined as configurable if:

- All needs and functions that can be satisfied by variants of a product family have been comprehensibly defined.
- All the technical parameters associated with such needs and functions have been clearly defined [1].

Furthermore, a configurable product family requires that the company has defined what it will offer and has created a limited solution space that will satisfy the customer's needs. Additionally, it needs to establish a link between the commercial and the technical model of the products.

A configuration system is a special kind of expert system, which differs from a traditional software system. It represents human knowledge and uses expert problemsolving methods, rather than methods that are based on mathematical modelling $[3,12]$. Configuration systems are software systems that create, use and maintain product models which allow a complete definition of all possible product outcomes and variations with a minimum of entries [3, 13]. A well maintained configuration system ensures a clear description of the products and communicates these to the sales person. In order to build a configuration system, it is necessary to model all relevant knowledge about the products in a form that can be incorporated into a configuration system.

Analysis and design models are often created when developing a product configurator. However, both models require an analysis language. To avoid the use of different modelling techniques, HAUG et al. propose the layout technique 'Vertical Aligned Class Diagrams' (VACD), which incorporate the use of 'Product Variant Masters' (PVM) into class diagrams. Investigations strongly indicate that the use of VACDs in configurator projects has the potential to increase efficiency, improve communication and reduce errors [14]. LIU et al. focus on the integration of reliability analysis and configuration at the component level. Possible failure causes obtained with a fault tree analysis (FTA) are mapped onto the product configuration network model via a functional model and a limitation matrix [15]. LI et al. created input and output matrices based on a positive reasoning rule model in order to resolve match conflicts between rulebased reasoning mechanisms and product manufacturing logic. Using a data-driven control strategy and conflict resolution methods, a product configuration-reasoning algorithm supporting the conflict resolution is given and exemplarily demonstrated [16]. In HELO's et al. opinion, existing product configurators are mainly used as sales tools, and fail to account for the requirements of the entire customer order fulfilment process. In this regard HELO et al. propose an Integrated Vehicle Configuration System

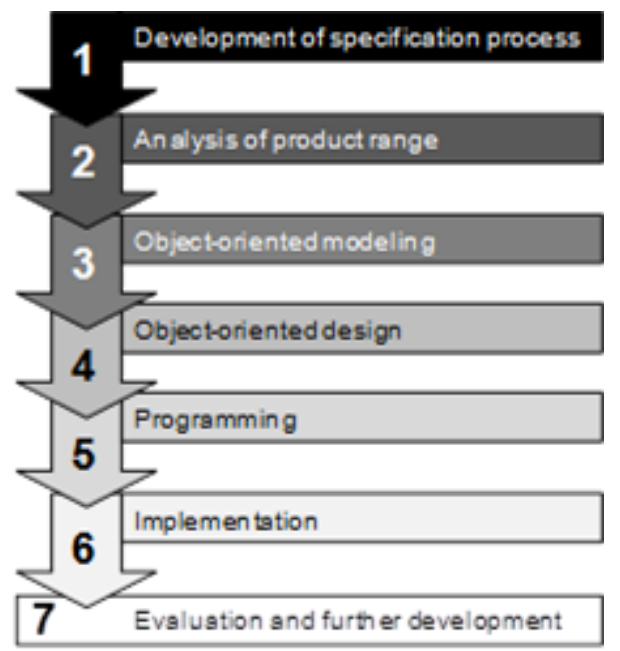

Figure 1: Procedure for developing configuration systems [3] 


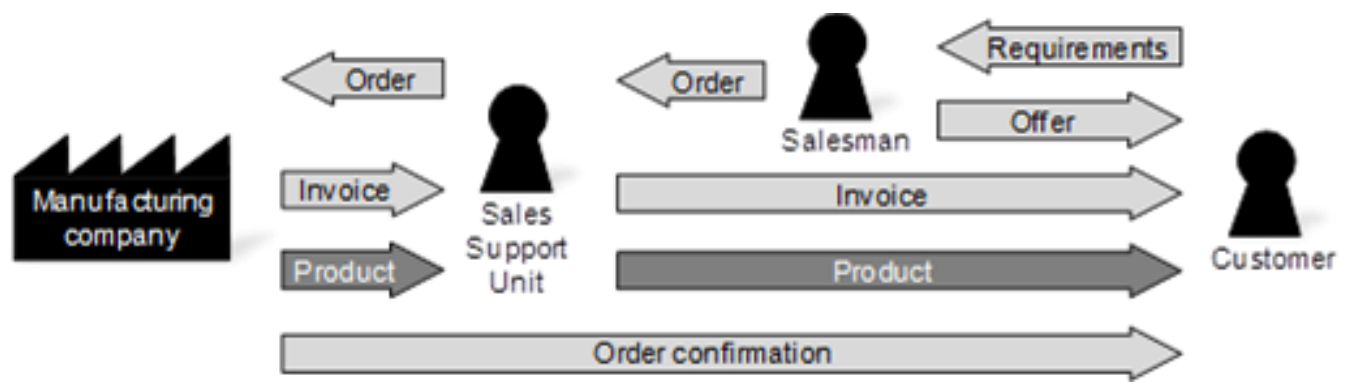

Figure 2: Information and material flow

(IVCS) to facilitate customer and order processing based on information from multiple domains in a mass customization environment. IVCS is based on combinations of selective and generative rules and supported by a comprehensive ontology framework [17].

Like product configuration systems, Product Data Management (PDM) systems handle the documentation, availability and the updating of data originated from the technical office, such as designs, BOM and simulations. In particular, PDM systems were created in order to support interfaces between different departments of a company. While the PDM is mainly meant to manage engineering product data, the product configuration system supports sales processes and connects them to the engineering and the production $[1,18,19]$.

For example, JIANG et al. propose a new approach to inventory shortage driven optimization for product configuration variation based on genetic algorithms. The approach adds impact costs, lead times and inventory factors to the traditional configuration optimization model and considers the effects on other orders when a component changes [20]. ELMARAGHY et al. study the effect of product modules structure on the corresponding globally distributed supply chain configuration. An integer linear decision support model is developed to determine the optimal location of global supply chain nodes by simultaneously considering the current exchange rate at various sites and the optimal modular product structure to be used in order to minimize the total cost [21]. OVERMEYER et al. use data mining in order to predict performance figures of alternative system configurations of manufacturing technologies. Using the performance figures different configurations of a system could be assessed and compared during the bidding phase [22].

\section{EFFECTS OF PRODUCT CONFGURATION ON ORDER PROCESSING}

HVAM defines a comprehensive seven phase procedure for developing configuration systems. Based on the object-oriented project life cycle (analysis, design, implementation and maintenance), the introduced approach further contains methods for analyzing the business processes to be supported by the configuration systems and proceedings for analysing and modelling the product range [3]. By following the defined steps, the methodology facilitates the development of product configurations. As shown in figure 1, first the specification process has to be defined (phase 1), after that the product range needs to be analyzed (phase 2), then an objectoriented analysis (OOA) model of the product configuration should be constructed (phase 3) and a configuration system has to be chosen, in order to adapt the OOA-model (phase 4). After the requirement specifications have been specified, the next steps consist of programming and testing (phase 5) and implementing (phase 6 the configuration system in the future specification process). Finally, the performance of the new specification process should be measured and the configuration system needs to be adjusted accordingly (phase 7).

The following subchapters describe the developing process of a product configuration system for a manufacturer of mass customized products. This case study has been conducted according to HVAM's framework and shows how product configuration could be used for optimizing order processing. Moreover, the impact of product configuration on order processing has been evaluated.

\subsection{Phase 1: Development of specification process}

In phase 1 the most important specification processes need to be identified, correspondingly, the requirements for the individual specification processes have to be formulated as well and compared to the present performance. Furthermore, a new specification process has to be designed.

Present processes, aims and requirements

The analysis of the specification processes aims at

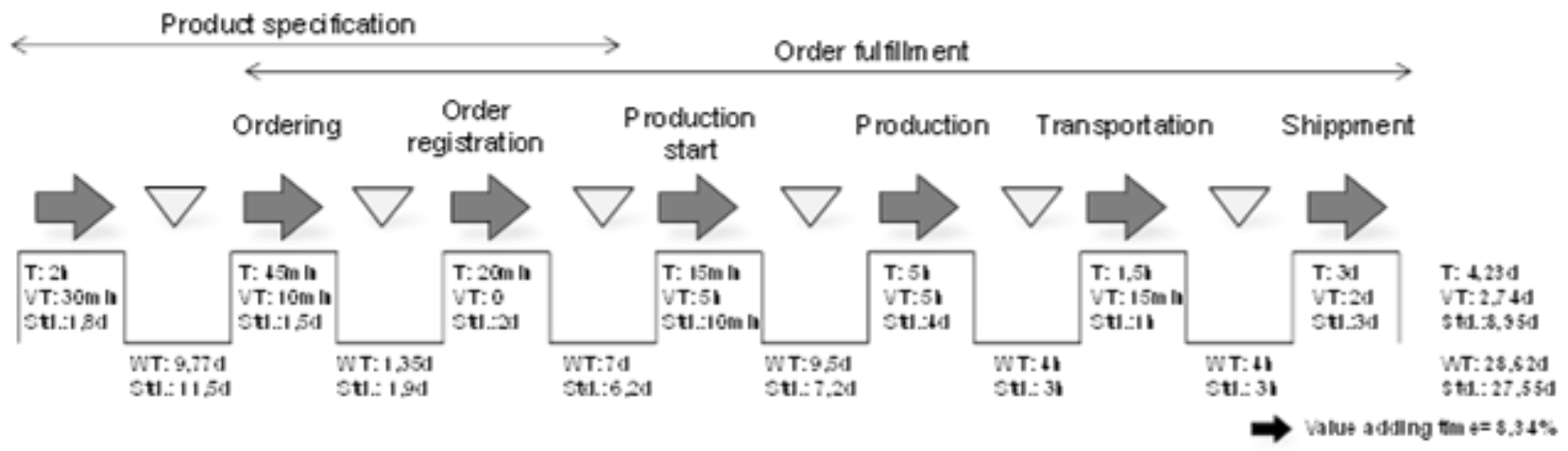


defining the specifications necessary to ensure that the ordered products are delivered in the right place at right time and in the right condition. A good starting point when analyzing the process is to identify necessary specifications in the product life-cycle and then to investigate activities used to generate each of them.

This study was done in a close cooperation with a company that manufactures mass customized goods. Being a leading global provider of equipment and industrial systems, the company possesses advanced technological know-how, but struggles with the handling of some of his business processes. The product chosen for evaluation is sold through Sales Support Units (SSU) located worldwide. The customer orders the product through salespeople working for the SSU (figure 2). The sales process most often begins with the customer calling the salesperson and asking for products or with the salesperson contacting the customer and adverting new ones.

The salesperson typically uses product brochures and manuals to educate the customer on the solutions the manufacturing company has to offer. Since product variants have already been defined in the pricing spreadsheet, the order decoupling line is customized to delivery, i.e. the customer selects between predefined alternatives of the product and can then define customized delivery options and payment agreements. If the customer is interested in buying a particular product, the salesperson consults the pricing list and makes an unofficial offer. If the customer feels that the offer is reasonable, they reach an agreement.

The Value Stream Mapping (VSM) technique was used in order to investigate the value adding time of the specification processes, production and delivery (figure 3). There, the VSM is divided between activities, presented by arrows and waiting times that separate the activities, presented by triangles. The measurements shown in the VSM are the average time the activity/waiting takes (T), the value adding time (VT) and the standard deviation of the duration (Std.). The time at the waiting station is never calculated as a value adding activity. The specification process begins with the specification activity and lasts until the production start is arranged, i.e. the right bill of material (BOM) has been found and adjusted and the order is ready to be processed. The order fulfilment process starts when the customer accepts the quotation offer, which means that it begins with the ordering activity and ends with the customer receiving the product. The shipment of the product is therefore included in the process. However, the shipping service is bought from an external company. Because of difficulties in estimating the value adding time of the shipment, it was decided that the value adding time would be the shortest amount of time needed for the product to be shipped. Any time which exceeds that is estimated as non-value adding.

The mostimportant VSM measurements are illustrated in table 1 . The measurements show that an expected order fulfilment time is 22,83 days. However, the standard deviation in the order fulfilment process is 23,20 days, which means that the order fulfilment can take up to more than twice as long. The measurements of the specification process show that 18,54 days pass from the moment when the salesmen make a quotation to the customer until the production can start. Approximately 9,77 of these days are due to time waiting for the customer to respond to the quotation offer, however, 8,35 days are explained by waiting time in the manufacturer's processes. The result is that only a $0,45 \%$ of the specification process time is value adding. The standard deviation of the specification process is 24,92 days. The time that has passed before the production starts is therefore unpredictable.

\begin{tabular}{|l|r|r|r|}
\cline { 2 - 4 } \multicolumn{1}{c|}{} & \multicolumn{1}{|l|}{ Total time } & \multicolumn{1}{l|}{ Order fulfillment } & \multicolumn{1}{l|}{ Specification process } \\
\hline $\mathrm{T}[\mathrm{h}]$ & 32,85 & 22,83 & 18,54 \\
\hline $\mathrm{VT}[\mathrm{h}]$ & 2,74 & 2,68 & 0,08 \\
\hline Std $[\mathrm{h}]$ & 36,50 & 23,20 & 24,92 \\
\hline $\mathrm{WT}[\mathrm{h}]$ & 28,62 & 18,85 & 18,12 \\
\hline $\mathrm{VT}[\%]$ & 8,34 & 11,73 & 0,45 \\
\hline
\end{tabular}

T: Time duration; VT: Value adding time; Std: Standard deviation; WT: Waiting time

Table 1: Results of VSM measurements

The time measurements of the product specification and the order fulfilment give a good idea of which non-value adding activities the process contains in a relative perspective to the value adding activities, pointing out where improvements would be most effective. The largest

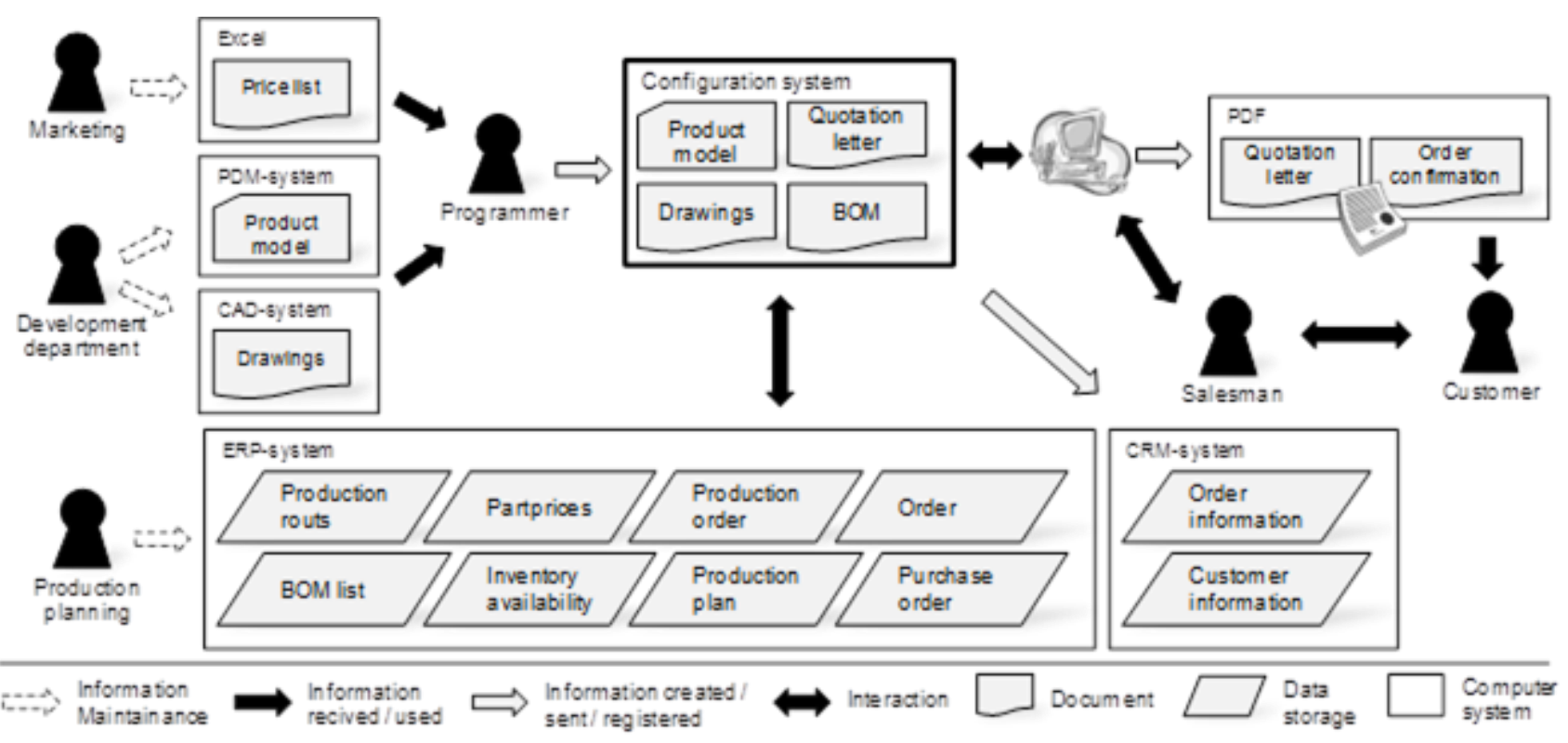

Figure 4: Design of new specification process 
amount of non-value adding time in the process is found in the waiting time, when the order is waiting to be processed. To shorten the lead time, the manufacturing company should therefore look into combining and automating some manufacturing activities. That should enable them to shorten or eliminate some of the waiting time between the activities, increase the value adding portion of the process and shorten the delivery time.

\section{Design of a new specification process}

In order to evaluate the effect of the product configuration on order processing, a new specification process has been designed. In the scenario, the salesperson is equipped with a configuration system that helps him to communicate the product range and supports the customer in her choice. The configuration system should automatically create a quotation letter. In addition, the configuration system interacts with the ERP-System receiving real time information regarding parts, prices and delivery times (figure 4).

The configuration system is accessed through a website. The customer tells the salesperson his needs and the salesperson uses the configuration system to find a solution which fulfils the customer's requirement. As product variants are selected, the configuration system rules out options that become invalid. The product variants will be expressed with figures and descriptions. When a product that fulfils the customer's wishes has been configured, the configuration system creates a quotation letter automatically.

The configuration system interacts with the ERP-System to get current information regarding products and delivery times. When a customer has accepted an offer, an order is automatically registered to the ERP-system. The technical information, such as BOM lists and lists of operations, can be transferred to the ERP manufacturing and planning modules. The BOM lists are not pre-defined, but are created as the products are configured. Changes made to product models are reflected in BOMs created from that point on. This avoids the need for changing hundreds of BOMs manually when adjustments to a product specification are made. The change is only made once in the product model.

In order to determine the cost of a product, data regarding the cost of each part are stored in the database. Prices are automatically calculated from the aggregated cost of all the items which the configured BOM contains and from the cost of the resources required to produce the product applying some specific, additional rules defined by the marketing side. This enables the company to calculate a more exact cost price.

\subsection{Phase 2: Analysis of product range}

A necessary condition for developing a configuration system is that the company has an overall view of the product family and that the product assortment can be structured in a configurable way. The Product Variant Master (PVM), introduced by HVAM, is an important prerequisite for facilitating the modelling process and can act as a platform of communication of the product range. Each functional area of the company may have different ways of describing the product assortment in relation to different aspects of the product life-cycle.

In phase 2, a PVM has to be developed, evaluated and placed in relation to the primary objectives and the process of developing a configuration system. At the end of this phase, the product variant master serves as a basis for the subsequent object-oriented analysis and modelling.
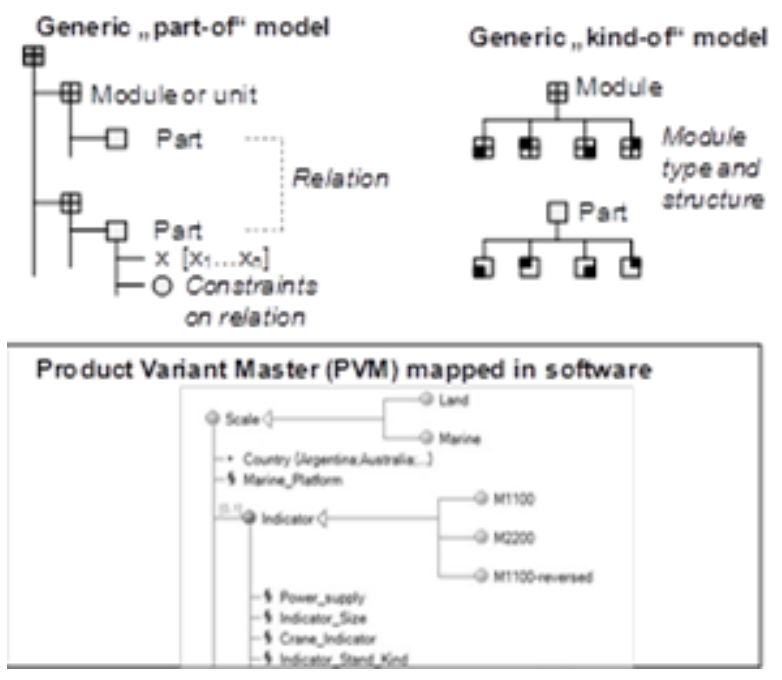

Figure 5: Principal notation and a small subset of a PVM [13]

The product family of the company chosen for evaluation has, compared with other product families of the company's product range, a simple product variation. To structure the product family, information regarding the products was gathered by interviewing employees that possess the necessaryknowledge of the product structure and by studying the available product documentation.

Finally, a complete PVM representing the product family has been structured according to the structure of the PVM-model. The PVM-model contains two parts (figure 5). The "part-of" model consists of those parts that appear in the entire product family. In that way, the model can also assign quantities to the parts that can further be characterized by a set of attributes describing their properties. The "kind-of" structure distinguis hes further the parts in different variants. The most important connections between the parts can be shown by adding lines between them and writing the rules characterizing their relationship. Figure 6 displays the notation and an extract of the PVM.

\subsection{Phase 3: Object-oriented modelling}

Having developed the PVM, an object-oriented analysis has to be created in phase 3 . The purpose is to develop the PVM further to an object oriented model to be implemented in the configuration system. Object-oriented modelling is a method for presenting knowledge. One of the most well known modelling methods is the unified modelling language notation (UML). UML describes object classes and their relationships with class diagrams.

Based on the structure of the PVM, classes have been subsequently grouped into subjects, which contain functions and/or procedures that use a common set of data. This approach enables structuring a complex system so that complexmodels can be handled easier. As products and processes are analyzed, the necessary product and system knowledge is documented for developing and maintaining the configuration system.

As the developed class diagram in figure 6 shows, the future configuration system contains a product model and classes that have been created to calculate the price and to create a quotation letter (sales model, part model, order handling model, routes model).

The class "customer", contains information regarding the customer and the payment agreements (sale model). Moreover, the "customer" class interacts with the product model to ensure that the right products are offered at 
different markets. The class "price" calculates the price of the product configured by accumulating the prices of all the components chosen. This class furthermore creates a product code and a description based on the chosen attributes. The quotation class then creates a standard quotation letter presenting the information from the customer and the price classes.

In addition, the order needs to be registered, whereby a production order needs to be sent to the right factory and a special order is to be made for the parts that are produced by a local supplier (order handling model). The class "product order" therefore has to "know" where each product is produced. When the orders have been registered, the product order collaborates with the class "order confirmation" that creates an order confirmation. The class "product order" contains both a BOM list and a list of operations.

The manufacturing of each product has been described in terms of operations (part model). The operations for the individual components of the product are standardized.

However, the routes for the assemblyare special for each order (assembly routes model). When the order arrives, the necessary resources are assigned to the product from the available resources class. The production sequence is then used to calculate the production time.

The class "BOM list" interacts with the class "availability of parts" (part model). If the parts are not all available in the inventory, the class interacts with the assembly routs model to see how long it will likely take to produce the part. The production of that part is then included in the production sequence and the production time as well. The $\mathrm{BOM}$ lists are divided both by products and by operations so that the different departments can have the BOM list relevant for their work.
As more products are added to the configuration system, it becomes necessary to include several product models. Some classes are then used in more than one product model, which increases the complexity. Therefore, the product models need to be clustered and set up in such a way that it helps the sales person to easily find the product she is looking for. As can be seen from the class diagram, there are a number of interactions between the subjects within the product model. The structure of the class diagram should decrease the complexity of these connections. It is furthermore necessary to design and describe the interfaces between the systems and the classes, both for the programmers to follow and in order to determine whether all the interactions are technically possible.

\subsection{Phase 4: Object-oriented design}

In phase 4 the analysis model obtained from the previous steps is converted into an implementation oriented design model. While in the phases before the focus was on how to make a model that provides the best representation of the product assortment, the viewpoint has now changed into how to implement the model into a configuration system.

Thus, the scope of this phase was to find configuration software that meets the demands of the company efficiently. Considering all relevant requirements, instead of developing a new configuration system from the ground up, a standard solution was chosen. It was decided to use software called Product Modeller ${ }^{\circledR}$ from Configit. The software allows a fast programmed prototype version of the product, it can easily be maintained and supports the integration to other systems of the company. With the chosen software, first versions of the configuration system were developed. After making the first prototype of the system, meetings with some of the relevant employees were held to receive feedback on the system and discuss

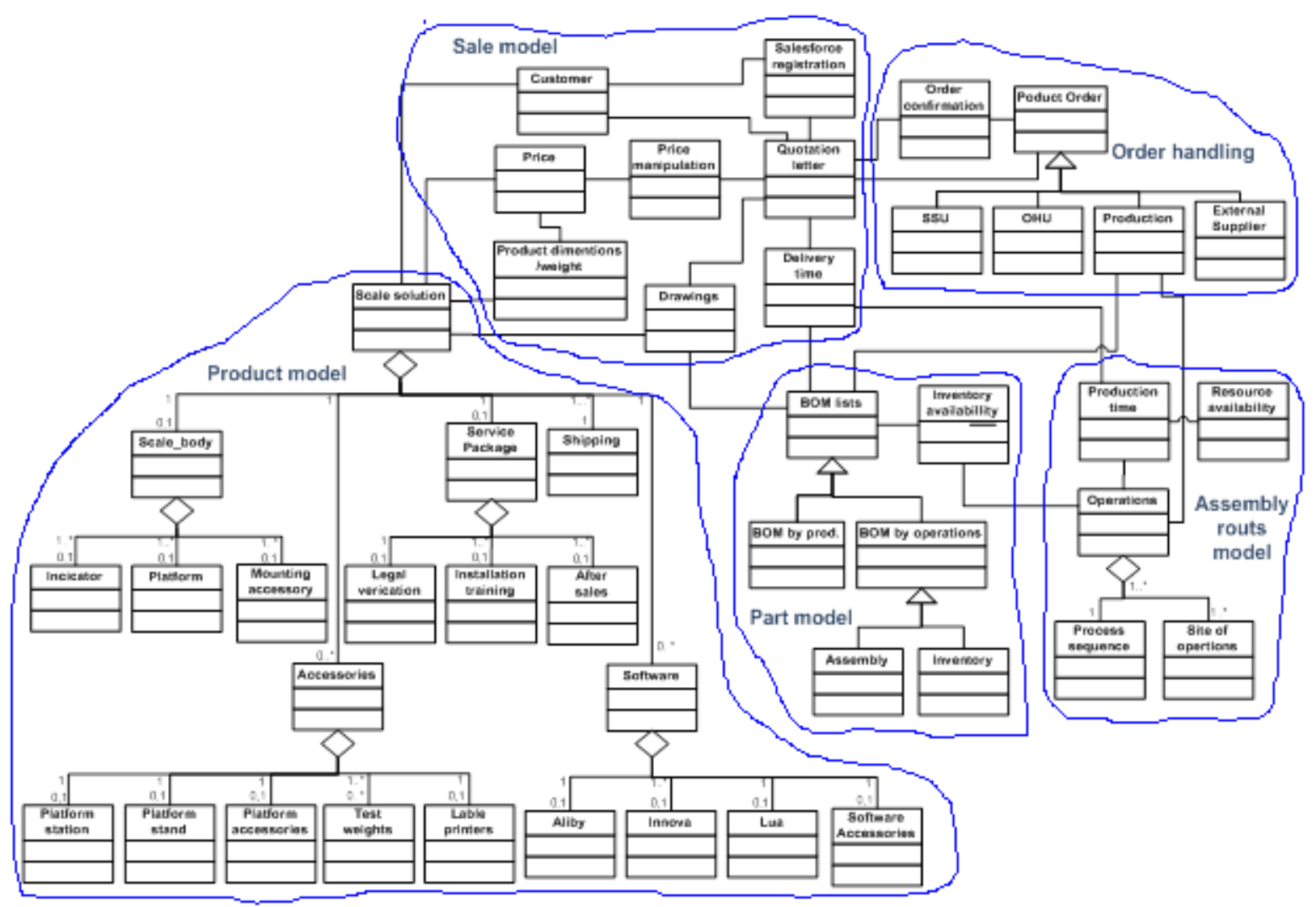

Figure 6: Class diagram of the configuration system 
further requirements.

\subsection{Phase 5 and 6: Programming and Implementation}

The programming phase (phase 5) aims at entering the expert-knowledge into the configuration system. In consideration with the previous requirement specification, the object-oriented model is transformed into an operating system which is capable of interacting with the other systems of the company. The objective of the implementation phase (phase 6) is to implement a configuration system that is accepted and used by all involved parties.

Based on the given documentation of the product model with the PVM, the configuration system was programmed by using the standard software Configit Product Modeller $\AA$. This software supports the fundamental principles of object-oriented technology and is therefore capable of handling class object relationships, inheritance and encapsulation. After the PVM had been integrated into the configuration system, the model was further developed. Prices, pictures and comments were added to provide further description of the product. Afterwards the model was compiled, launched and tested.

\subsection{Phase 7: Evaluation and suggestions for further developments}

In order to identify the possibilities offered by product configuration, a gap analysis has been conducted in phase 7 , measuring the gap between the value adding time of the current processes using product configuration and those that do not. The results of the gap analysis are based on interviews with employees and analys es of the process.

Several sources of non-value adding activities and waste in the processes have been identified in phase 1. By implementing a configuration system and automating some of the manual paperwork, the objective is to increase the performance of the specification processes. It has been recognized that many of the activities in the office involve various non-value adding elements. The productivity of employees can be improved by automating activities in the specification processes. Furthermore, the standard deviation of the duration of the processes can be reduced further by avoiding errors thus ensuring better quality of information and documents. However, it is recognized that the waiting time in the process, i.e. time when the order is waiting to be handled between activities, is usually significantly more time-consuming than the non-value adding time during the activities. Therefore, by either combining processes or by eliminating processes with automation, some of the waiting stations could be eliminated.

It is an objective of the product configuration to decrease the non-value adding activities and to shorten the duration of the process. Having reached the target performances, the VSM for the process might look like illustrated in figure 7. As the figure shows, the duration of the process, i.e. from the moment of creating the specification and making the customer a quotation until the moment the customer receives the offer, has decreased from 4,2 days to 3,7 days and the portion of the value adding activities has increased from $8,34 \%$ to $13,1 \%$. The value stream of the process has improved and the specifications are transferred to production without interruptions.

A gap map is made for the VSM of the order fulfilment process and the specification process. As can be seen from the gap map presented in table 2 , the duration of the processes shortens significantly when using the product configuration system. The duration of the order fulfilment process can be kept below 14 days, which means that the customer receives the product in time. The value adding time increases both for the order fulfilment process and for the specification process. Except for the waiting time involved in waiting for the customer's decision, the order can be transferred directly to the production.

\begin{tabular}{|l|r|r|r|}
\cline { 2 - 4 } \multicolumn{1}{c|}{} & \multicolumn{1}{l|}{$\begin{array}{l}\text { Current } \\
\text { performance }\end{array}$} & Target performance & Value adding gap \\
\cline { 2 - 4 } \multicolumn{1}{c|}{} & \multicolumn{3}{|c|}{ Order fulfilment } \\
\hline T [h] & 22.83 & 13,93 & 8,90 \\
\hline VT [h] & 2,68 & 2,68 & 0,00 \\
\hline Std [h] & 23,20 & 11,26 & 11,93 \\
\hline WT [h] & 18,85 & 10,25 & 8,60 \\
\hline VT [\%] & $\mathbf{1 1 , 7 3}$ & \multicolumn{3}{|c|}{$\mathbf{1 9 , 2 2}$} \\
\hline & \multicolumn{3}{|c|}{ Specification process } \\
\hline T [h] & 18,54 & \multicolumn{3}{|c|}{7,08} & 11,45 \\
\hline VT [h] & 0,08 & 0,08 & 0,00 \\
\hline Std [h] & 24,92 & 8,60 & 16,32 \\
\hline WT [h] & 18,12 & $\mathbf{3}$ & 11,12 \\
\hline VT [\%] & $\mathbf{0 , 4 5}$ & $\mathbf{9 , 4 1}$ & $\mathbf{3}$ \\
\hline
\end{tabular}

T: Time duration; VT: Value adding time; Std: Standard deviation; WT: Waiting time

Table 2: Results of VSM measurements

\section{SUMMARY AND CONCLUSION}

In order to evaluate the effects of product configuration on order processing, a study has been conducted. Thereby, a product configuration system has been modelled for a manufacturer of mass customized products and its benefits for the order processing have been evaluated.

The case product family and the interdependences between the components have been modelled and programmed in a standard configuration system. Additionally, data regarding price and product identification have been added to the components enabling the creation of a quotation letter which

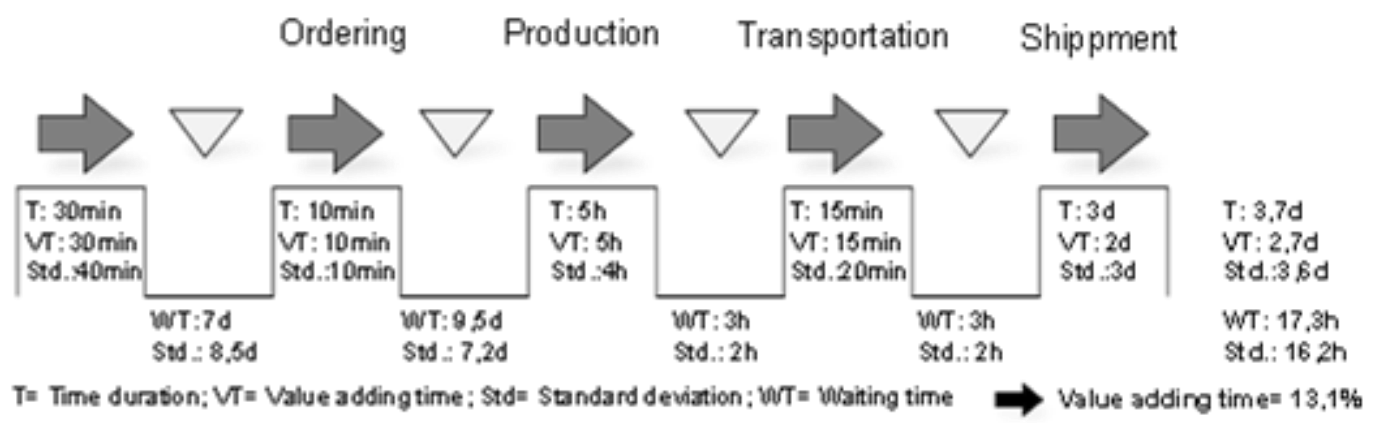

Figure 7: Target performance from the value stream 
automaticallycalculates prices. This configuration system enables the salesperson to present the product to the customer, to choose between attributes and to get an overview of the entire product range, all in one place. Furthermore, it makes it possible to determine invalid specifications and to enforce a specification of the mandatory required attributes. Hence, this configuration system supports the specification process by enabling better product representation, automating the process of making quotations, reducing errors, as well as decreasing resource consumption and lead time of making quotations.

As the case study shows, making the product configurable is an important step for increasing the efficiency in the specification processes and communicating the product to sales people and the customers:

- Identifying opportunities for redesigning components in a more modular way can lead to a more simple specification process and possibly to a reduction of components and inventory.

- Observation of the specification process in the case company showed that integrating structure in the product specifications increases value adding time of the value stream by optimizing the efficiency of the production process.

- In addition, it was realized that unstructured documents regarding alternative product variants result in a lack of quality of the product specifications. Thus, unstructured product documentation can act as a source of errors for the processes and may be responsible for long lead times.

- Furthermore, the implementation of a configuration system can ensure a faster learning process and a better product presentation by avoiding the often unfulfilling and inconsistent product documentation available to sales people. .

Applying a configuration system to the specification process can lead to significant improvements of the specification processes and can strengthen the long term competitiveness of the company. The shorter lead time and improved quality of the specifications lead to improved quality, increased productivity and reduced lead times in production as well, as the production is very depending on correct and on time specifications. However, to utilize the opportunities that a configuration system creates to their full extent, it is necessary to look across departmental boundaries and see the process as a whole.

\section{REFERENCES}

[1] Forza, C.; Salvador, F.: Product information management for mass customization: Connecting customer, front-office and back-office for fast and efficient customization. Basingstoke [England]; New York: Palgrave Macmillan, 2007

[2] Ericsson, A.; Erixon, G.: Controlling design variants modular product platforms. Dearborn, Michigan: Society of Manufacturing Engineers, 1999

[3] Hvam, L.; Mortensen, N.H.; Riis, J.: Product customization, Springer, Berlin, London, 2008

[4] Baldwin, C. V.; Clark, K. B.: Modularisierung: Ein Konzept wird universell. HARVARD BUSINESS MANAGER, 20(2), 1998, pp. 39-48

[5] Miller, T. D.: Modular engineering an approach to structuring business with coherent, modular architectures of artifacts, activities, and knowledge. Lyngby, 2001
[6] Victor, B.; Boynton, A. C.: Invented here: Maximizing your organization's internal growth and profitability. Boston: Harvard Business School Publishing, 1998

[7] Zhang, $X$ : Simultaneous configuration of platform products and manufacturing supply chains. International Journal of Production Research, 46(21), 2008, pp. 6137

[8] Ulrich, K. T.; Tung, K.: Fundamentals of product modularity. Cambridge, Mass.: Sloan School of Management, Massachusetts Institute of Technology, 1991

[9] Hansen, B. L.: Development of industrial variant specification systems. DTU), 2003

[10] Ehrlenspiel, K.; Kiewert, A.; Lindemann, U. Kostengünstig entwickeln und konstruieren. Kostenmanagement bei der integrierten Produktentwicklung, 2005

[11] Yang, W. Z.; Xie, S. Q.; Ai, Q. S.; Zhou, Z. D.: Recent development on product modelling: A review. International Journal of Production Research, 46(21), 2008, pp. 6055-6085

[12] Jackson, P.: Introduction to expert systems. Harlow, England, Reading Mass.: Addison-Wesley, 1999

[13] Bourke, R.W.: Configurators: A status report. Apics the performance advantage, 8 (5), 1998, pp. 42-45

[14] Haug, A.; Hvam, L.; Mortensen, N.H.: A layout technique for class diagrams to be used in product configuration projects. Computers in Industry, 61 (2010), pp. 409.-418

[15] Liu, Y., Liu, Z.: An integration method for reliability analyses and product configuration, In: International Journal of Advanced Manufacturing Technology (2010) 50, pp. 831-841

[16] Li, N.; Liu, D.; Zhang, J.; Chen, Y.: A method of rule match conflict resolution for product configuration in manufacturing. International Journal of Computer Integrated Manufacturing, Vol. 22, No. 3, 2009, pp. 210-224

[17] Helo, P.T.; Xu, Q.L.; Kyllönen, S.J.; Jiao, R.J.: Integrated Vehicle Configuration System Connecting the domains of mass customization. Computers in Industry 61 (2010), pp. 44-52

[18] Rimpau, C.; Reinhart, G.: Knowledge-based risk evaluation during the offer calculation of customised products. Production Engineering Research and Development (2010), 4, pp. 515-524

[19] Denkena, B.; Henning, H.; Lorenzen, L.-E.: Genetics and intelligence: new approach in production engineering. Production Engineering Research and Development (2010), 4, pp. 65-73

[20] Jiang, Z.; Xuanyuan, S.; Li, L.; Li, Z.: Inventoryshortage driven optimization for product configuration variation. International Journal of Production Research, 2010, pp. 1-16

[21] ElMaraghy, H.A.; Mahmoudi, N.: Concurrent design of product modules structure and global supply chain configurators. Intrernational Journal of Computer Integrated Manufacturing, Vol. 22, No. 6, 2009, pp. 483-493

[22] Overmeyer, L; Dreyer, J.; Altmann, D.: Data mining based configurations of cyclically interlinked production systems. CIRP Annals - Manufacturing Technology 59 (2010), pp. 493-496 